\title{
Measuring the Impacts of Quality of Work Life Indicators on the Marketing Representatives of Pharmaceutical Industries
}

\author{
Kazi Nazmul Huda \\ Department of Business Administration, Southern University Bangladesh, \\ 739/A, Mehedibag Road, Chittagong 4000, Bangladesh
}

Received: November 30, 2016; Accepted: December 20, 2016; Published (Web): March 19, 2017

\begin{abstract}
In modern Human Resource Management (HRM) practice, the concept of 'Quality of Work Life' (QWL) is relatively a new strategy for employee retention. The idea of QWL is developed upon the increasing importance of reducing employee turnover rate in a highly competitive market. Better QWL practice in sales and marketing oriented companies is inevitable to ensure employee productivity and therefore needs to be studied in detail. The core objective of the study was to measure the impact of QWL variables on the lives of Marketing Representatives (MR) of pharmaceutical companies. First, the variables influencing QWL are elaborated with the help of extensive literature review. Then this study tried to identify the current scenario of QWL Practices in ten renowned pharmaceutical companies through a survey of 112 MRs. This was supplemented with in-depth interviews of HR executives of three different companies. The study discovered job stress as a high priority indicator of QWL. The research also revealed organizational atmosphere based on fairness, experience sharing culture, employee suggestion scheme, opportunity to use skill and satisfactory reward system as influential determinants of QWL. This paper recommends the installation of QWL practices in other pharmaceutical companies with few short and long-term suggestions. There is room for conceptualizing and actualizing standard QWL practice in the Bangladeshi pharmaceutical companies. An initiative like this one will encourage discussion and debates in applying much needed QWL practices in other sectors.
\end{abstract}

Key words: Human Resource Management, Quality of Work Life, Marketing Representatives, Pharmaceutical Company.

\section{Prologue}

Pharmaceutical industry is the second largest export-oriented earning sector and the top most technologically advanced manufacturing sector of Bangladesh. Around 278 licensed pharmaceutical companies of different sizes are the heart of this sector that proudly offers 27287 registered Allopathic drug to meet $98 \%$ of the domestic demand (DGDA, 2015). The size of the industry is 117 billion BDT with the annual growth potential of $11.37 \%$ (Hossain \& Shoaib, 2014). By 2020, the industry may reach the mark of total sales of 1.4 trillion USD. More than 30 industries export products to about 130 countries around the globe, which are mostly in Germany, USA, France, Italy, UK, Canada, Netherlands, and Denmark (Market Pulse, 2016). It also contributes to the largest recruitment in sales and marketing positions with an employment of approximately 115,000 workers. According to Bangladesh Pharmaceutical Society (BPS), the truth behind the success of the sector is its skilled, knowledgeable, and dedicated professionals. Collective efforts of its workers, staffs, and owners are the key forces behind the extraordinary achievements of this industry. The industry is highly human resource based, as it requires highly skilled people to develop, manufacture and sale of its products. Marketing Representatives (MR) are the frontline employees who are responsible for prospecting the sales of such extended product line. They are the key force for marketing and sales functions of this sector (Habib and Alam, 2011). It can be argued that, target oriented professions can be stressful as they need to put their

Correspondence to: Kazi Nazmul Huda, E-mail: knhuda@yahoo.com 
utmost effort to meet the sales target. To remain engaged and productive in this highly competitive environment, MRs need special care. Quality of work life is a popular human resource management strategy to improve the life of highly engaged employees.

Quality of work life is a commitment of an organization to improve the working condition and wellbeing of their employees (Carlson, 1981). Existing studies found a strong correlation between QWL and organizational productivity (Bagtasos, 2011) and employee's job satisfaction (Rice et al., 1985). QWL is recognized as an important aspect of job performance in healthcare organizations (Cole et al., 2005). Pharmaceutical industry is the top among the healthcare industry of Bangladesh where MRs are the most important human resource. MRs spend their maximum time attaining sales calls - a job without time boundary. They need to visit the doctors during day and night and become stressed both at work and in personal life. To keep them effective and more focused towards work, QWL issues should be properly applied as a success factor of pharmaceutical industries (Habib and Alam, 2011). However, there is lack of studies on the applicability of QWL theories in Bangladesh. The current study will try to explore the current scenario of QWL practices among the pharmaceutical companies with respect to the influential determinants of the same.

\section{Research Question}

1) What are the indicators of QWL in pharmaceutical industries in Bangladesh?

2) How do MRs of pharmaceutical industries rank and prioritize those determinants?

\section{Review of literature}

Quality of Work Life (QWL) is an important issue in the "Fortune 500 Companies" and gaining attention among the MNCs all around the globe. It is becoming a revolutionary corporate philosophy to improve the work life in a high performing culture and in a rapidly changing environment. QWL strategies raise organizational image that leads to better talent acquisition and retention (Ballou and Godwin, 2007). Many researches on QWL have found a significant relationship between job satisfactions with employees work life (Rice et al., 1985). According to Sirgy et al., (2001) employee perceives QWL as mostly ensured by physical facilities of workplace, fair compensation, collaborative relationship among them, participation in decision-making, and self-esteem. Career development opportunity at work is also an effective QWL issue suggested by many researchers like Li and Yeo (2011). Yeo and Li (2011) suggested few important determinants of QWL i.e. organizational culture with good governance, training and learning opportunity, mentorship of the superiors, feedback based appraisal, collaborative environment, job identity, etc. For the sustainability of an organization, management must address the QWL by ensuring employees standard of living, environment, workplace health and safety, wellbeing during working hours, potentials for career advancement, and mostly the work/life balance issues (Ballou and Godwin, 2007). Bragard et al., (2012) conducted a research on cancer doctors of Belgium and found that QWL was ensured through reduction of working hours, increasing organizational support, and change in leadership style. Workers' wellbeing through QWL interventions is also helpful for the organizational performances. Padala and Suryanarayana (2010) offered two dimensions of QWL. They classified physical working conditions, employees' welfare, employee assistance, job factors, and financial factors under 'Classical Dimension' and collective bargaining, industrial safety and health, grievance management, quality circles, work-life balance, workers' participation in management under 'Contemporary Dimension'. Yadav and Khanna (2014) authored an extensive literature review based article and classified job satisfaction, compensation, occupational safety \& health and career opportunity as extremely used variables of QWL by the researchers.

Existing studies like Bragard et al., 2012; Vagharseyyedin et al., 2011; Saklani, 2010; Johnsrud, 2006; Gnanayudam and Dharmasiri, 2007; Tabassum et al.,2011; Bolhari et al., 2011; Kiriago and Bwisa, 2013; Nair, 2013, Sadri and Goveas, 2013 and Mohammadi and Shahrabi, 2013 have succeeded to discover the condition of QWL of different professionals like Doctors, Iranian Nurses, non management working class of India, University Faculties, Apparel Industry Workers, Female Bankers, 
IT professionals, petrol pump attendants, college teachers, freight forwarding professionals, and government service holders of Iran. However, no studies have ever been conducted on MRs of pharmaceutical companies. Again, most existing QWL studies are for the developed countries. Habib and Alam, 2011; Hossain and Shoaib, 2013; and Akter,
2015 on their article on Bangladesh studied the prospects, contributions, opportunities, and challenges of this sector but not on the welfare of the professionals working in this industry. This study has endeavored to fill the gaps of previous researches.

\section{Table 1. Variables of quality of work life.}

\begin{tabular}{|c|c|c|c|}
\hline Sl.No. & Variables & Code & References \\
\hline 1 & Satisfactory working condition & $\mathrm{X}_{1}$ & Padala and Suryanarayana (2010) \\
\hline 2 & Practice of fairness in the organization & $\mathrm{X}_{2}$ & Sirgy et al. (2001), Krueger et al. (2002) \\
\hline 3 & Job security provided by the organization & $\mathrm{X}_{3}$ & Sirgy et al. (2001), Padala and Suryanarayana (2010) \\
\hline 4 & Employees comments \& suggestion scheme & $\mathrm{X}_{4}$ & Padala and Suryanarayana (2010) \\
\hline 5 & Employee's participation in decision making & $\mathrm{X}_{5}$ & Padala and Suryanarayana (2010) \\
\hline 6 & Fair grievance management & $\mathrm{X}_{6}$ & Padala and Suryanarayana (2010) \\
\hline 7 & Standard work time allocation & $\mathrm{X}_{7}$ & Bragard et al. (2012) \\
\hline 8 & Stress free work & $\mathrm{X}_{8}$ & $\begin{array}{l}\text { Cardiff" University's QWL survey (2008), Krueger } \\
\text { et al. (2002) }\end{array}$ \\
\hline 9 & Learning opportunity & $\mathrm{X}_{9}$ & Yeo and $\mathrm{Li}(2011)$ \\
\hline 10 & Opportunity to use of skill \& talents & $\mathrm{X}_{10}$ & Krueger et al. (2002) \\
\hline 11 & Compensation conforms standard of living & $\mathrm{X}_{11}$ & Bagtasos (2011) \\
\hline 12 & Satisfactory reward system & $\mathrm{X}_{12}$ & Padala and Suryanarayana (2010) \\
\hline 13 & Merit based performance appraisal & $\mathrm{X}_{13}$ & Yeo and Li (2011) \\
\hline 14 & Harmonious relationship among the colleagues & $\mathrm{X}_{14}$ & $\begin{array}{l}\text { Padala and Suryanarayana (2010), Parker et al. } \\
\text { (2003), Kaushik and Tonk (2008) }\end{array}$ \\
\hline 15 & Experience Sharing Culture & $\mathrm{X}_{15}$ & Padala and Suryanarayana (2010) \\
\hline 16 & Good career prospect & $\mathrm{X}_{16}$ & Li and Yeo (2011), Bagtasos (2011). \\
\hline 17 & Social Dignity & $\mathrm{X}_{17}$ & $\begin{array}{l}\text { Vagharseyyedin et al. (2011); Yadav and Khanna } \\
\text { (2014); Chander and Singh (1993). }\end{array}$ \\
\hline
\end{tabular}

Source: Literature Review by the author

\section{Methodology}

The methodology of this study was designed to address the research questions . The study is descriptive in nature, followed by inductive research approach and a survey based research strategy. The methodological choice of the research is quantitative. The survey intervenes to collect required quantitative information and data through structured questionnaire. An extensive literature review was conducted to identify the most common QWL variables (Table 1) and the questionnaire was developed based on the identified variables. Total 112 Marketing representatives (MRs) of different pharmaceutical companies were interviewed. MRs are the front line employees who are mostly assigned for direct selling of pharmaceutical products. They mostly take the hardship to work outdoor for prospecting, and qualifying sales. With a view to making the study informative and representative, a close-ended questionnaire was designed.

To measure the degree of influence of variables listed in table 1, a questionnaire has been prepared with 17 questions and a 5-point likert rating scale with = strongly agree and = strongly disagree have been used to capture the opinion of the respondents. The respondents were all male MRs involved in direct sales of pharmaceutical products for last five years or more. Data analysis of the study was conducted through 
multivariate analysis technique, specifically through Exploratory Factor Analysis (EFA) with the support of SPSS. Ranking of the relevant variables of QWL (Table 1) was considered based on the loading value (greater than 0.50) of each item. Higher loading value is considered as higher degree of impact on QWL of MRs and vice versa. Respondents were asked about their feelings of QWL in terms of the variables i.e. are they satisfied about their working condition, fairness in organizational culture in the organization, their feelings about job security, and so on. The survey was carried out between $1^{\text {st }}$ March and $1^{\text {st }}$ April, 2016.

\section{Data analysis}

Factor analysis was conducted, as it is an effective statistical tool used to describe variability among observed and correlated variables in terms of a potentially lower number of unobserved variables. Principal Component Analysis was used primarily on seventeen (17) explored variables (Table 1). KMO value, which shows the level of data adequacy, was, found to be 0.835 and thus the data can be used for EFA. Our results found that, these 17 variables in combination can explain more than $61.45 \%$ of the total variation of QWL of MRs. Strict decision was taken to drop items having loading less than 0.50 or cross loaded in more than one factor/dimension (as suggested by Hair et al., 2010). In the first stage of EFA, variable namely " $\mathrm{X}_{6}$-Fair Grievance Management was found to be cross-loaded (higher loading in two dimensions).The above-mentioned variable has been dropped from the study.

After dropping $\mathrm{X}_{6}$ variable and re-running the EFA, KMO value is found 0.817 , which shows the strength of data adequacy of the research. Principal component analysis has clustered remaining 16 variables under four factors and these factors covered around $61.68 \%$ of the total variance. Factor loading of the variables determining the degree of significance of each factor and the Eigen value and percentage of variation explained by the factor are shown in Table 2 .

Table 2. Factor summary: with their loading values and ranks.

\begin{tabular}{|c|c|c|c|c|}
\hline Factor & Variables & $\begin{array}{c}\text { Loading } \\
\text { Value (rank) }\end{array}$ & Eigenvalue & $\begin{array}{c}\text { Percentage of Variation } \\
\text { Explained }\end{array}$ \\
\hline F 1 & Learning & $0.703\left(8^{\text {th }}\right)$ & & \\
\hline \multirow{6}{*}{$\begin{array}{c}\text { Employee } \\
\text { Development } \\
\text { Factor }\end{array}$} & Compensation & $0.649\left(12^{\text {th }}\right)$ & & \\
\hline & Reward & $0.707\left(7^{\text {th }}\right)$ & & \\
\hline & Performance appraisal & $0.696\left(9^{\text {th }}\right)$ & 36.825 & 22.615 \\
\hline & Relationship & $0.598\left(13^{\text {th }}\right)$ & & \\
\hline & Sharing Culture & $0.735\left(4^{\text {th }}\right)$ & & \\
\hline & Participation & $0.693\left(10^{\text {th }}\right)$ & & \\
\hline F2 & Working condition & $0.696\left(9^{\text {th }}\right)$ & & \\
\hline \multirow{5}{*}{$\begin{array}{l}\text { Motivational } \\
\text { Factor }\end{array}$} & Job security & $0.715\left(6^{\text {th }}\right)$ & & \\
\hline & Suggestion scheme & $0.721\left(5^{\text {th }}\right)$ & & \\
\hline & Career prospect & $0.673\left(11^{\text {th }}\right)$ & 9.154 & 20.880 \\
\hline & Social Dignity & $0.561\left(14^{\mathrm{th}}\right)$ & & \\
\hline & Work Time & $0.537\left(15^{\text {th }}\right)$ & & \\
\hline F3 & Fairness & $0.739\left(3^{\text {rd }}\right)$ & 8.518 & 9.621 \\
\hline \multicolumn{5}{|l|}{ Fairness Factor } \\
\hline F4 & Stress free work & $0.752\left(1^{\mathrm{st}}\right)$ & 7.192 & 8.573 \\
\hline $\begin{array}{l}\text { Occupational } \\
\text { Stress Factor }\end{array}$ & Skill & $0.740\left(2^{\text {nd }}\right)$ & & \\
\hline
\end{tabular}

Source: Author's own calculation compiled from SPSS 20 
Given results provide statistical evidences to support the newly identified four factors of QWL as coded $F_{1}$, $\mathrm{F}_{2}, \mathrm{~F}_{3}$ and $\mathrm{F}_{4}$ (Table 2). This shows that, these variables have $61.68 \%$ impact on ensuring QWL. Variables under factor 1 are learning, compensation, reward, performance appraisal, relationship, sharing culture and participation. Percentage of variation explained by these variables is 36.825 that show significant influence of QWL of MRs. Factor 2 contains six variables working condition, job security, suggestion scheme, career prospect and social dignity with the eigenvalue of 9.154 and the percentage of variation explained is $20.880 \%$. The presence of these factors may increase the level of motivation of MRs. Factor 3 contains only one variable, namely fairness. The eigenvalue of this factor is found to be 8.518 and the percentage of variation explained at $9.621 \%$. Factor 4 contains only two variables namely stressful work and opportunity to use skill. The eigenvalue of this factor is found to be 7.192 and the percentage of variation explained at $8.573 \%$.

\section{Discussion}

The study shows a clear picture of the importance of QWL variables on the MRs of pharmaceutical companies of Bangladesh. The main findings of the study are:

1. Four QWL factors and sixteen relevant variables are revealed. The value of cronbach alpha judges the reliability of the model that is 0.82 . This high alpha value justifies the reliability and internal consistency of the proposed model. Findings of these sixteen indicators also answer the first research question of the study.

2. Loading values of all explored variables are greater than 0.50 (cut-off value) and found to have positive relation to ensure QWL.

3. Some variables such as stressful work, opportunity to use skill and experience sharing culture, reward system and learning opportunity are with the higher loading value (more than 0.70 ).

The study reveals four factors and 16 variables relevant to QWL of MRs in the pharmaceutical companies and the factor loadings of the variables are positive. The Factor 1, which is named 'Employee Development 'factor includes 7 variables i.e. $X_{5}, X_{9}$, $X_{11}, X_{12}, X_{13}, X_{14}$, and $X_{15}$. As the factor contains the highest eigenvalue (36.825), the percentage of variation explained is the highest amongst the four factors, and none of the other factors is nearer to it. Therefore, it is proved that factor 1 could have high impact in ensuring QWL of the MRs. In this factor, variable $\mathrm{X}_{15}$ culture of experience sharing by the colleagues, and $\mathrm{X}_{9}$ learning opportunity in the organization contains the higher loading values with the ranking of $4^{\text {th }}$ and $8^{\text {th }}$ respectively (Table 2). These may happen as most of the companies arranges in house and off the job training in a form of workshops, get together program and seminars. $\mathrm{X}_{12}$ satisfactory reward system is also at the top chart with the ranking order $7^{\text {th }}$ as most of the top ranking companies are offering attractive incentive programs for the MRs.

Factor 1 also contains variable $\mathrm{X}_{14}$ (harmonious relationship among the colleagues) which is holding one of the lowest loading values (.59) and ranked as least influencing variable. It reflects the poor nature of interpersonal relationship among the MRs. It is perhaps because of the existence of competitive corporate culture among the MRs where individual performance is given more importance than teamwork. Looking at the character of these variables it could be stated that, the QWL of the MRs could be ensured through the employee development factors if learning, sharing and rewarding culture is maintained.

Another important variable of factor 1 is merit based performance appraisal $\left(\mathrm{X}_{13)}\right.$. According to the loading value, it is placed at $9^{\text {th }}$ position. The result denotes that, the pharmaceutical companies are maintaining their appraisal system based on the merit and performance of the MRs. At the time of interview, the MRs have shared that, their incentive and performance bonus package is fully based on target achievement. Variable coded $\mathrm{X}_{5}$, (employee's participation in decision making) also placed in the top ten-order (ranked $10^{\text {th }}$ ). It may mean that MRs prefer to participate in decision-making process. This may happen because they are the only front line sales executive of the companies and thus management have 
to rely on MRs for market information, which can be used for planning and goal setting. Best practice of employee development factors may offer a work environment where employee development could be ensured through result oriented reward system, participation in decision-making, and mostly by promoting learning and experience sharing culture among the MRs.

Factor 2, which is named as Motivational Factor includes, six variables $\mathrm{X}_{1}, \mathrm{X}_{3}, \mathrm{X}_{4}, \mathrm{X}_{7}, \mathrm{X}_{16}$, and $\mathrm{X}_{17}$. The eigenvalue of this factor is 9.154 and the percentage of variation explained 20.88\%. The Motivational factor contains six important issues, 'employees' comments, and suggestion scheme' is a top priority. It means the MRs of the sample pharmaceutical companies feel free to offer comments and suggestions about the development of their work environment. Variable $\mathrm{X}_{3}$, and $\mathrm{X}_{1}$, namely job security provided by the organization, and satisfactory working condition, respectably, contains high loading values with the ranking of $6^{\text {th }}$ and $9^{\text {th }}$ (Table 2). Nonfinancial benefit like the stated ones may motivate MRs positively. Variable $\mathrm{X}_{16}$ (good career prospect in this profession), ranked $11^{\text {th }}$ with comparatively lower loading value. This could happen as the prospect of reaching at higher level of organizational structure is very limited and most of the senior positions are directly filled in. Such practice discourages the MRs as they remain in the same position for a long time and feel lack of esteem. The social dignity variable of factor 2 , is ranked poorly in the category $\left(14^{\text {th }}\right)$. It is important to note that, sales job in Bangladesh has been viewed as an inferior profession (Huda and Azad, 2015). As the MRs feel low esteem about their profession, increasing the social dignity of the profession may raise the selfesteem of the MRs which will be helpful to change the mindset of the potential clients towards them. Item named 'Standard work time allocation' also contains low loading value (.537) with second last position in the ranking. It is a fact that most of the MRs to work long hours (mostly at night) as most of their clients (Doctors) prolong their practices until midnight.

Factor 3, which is named as fairness factor, contains only one variable $\left(\mathrm{X}_{2}\right)$ with high loading value (.739). It signifies the necessity of fairness in the organization. This variable is in the third position as the
MRs feel that their work motivation highly depends on acceptable fair corporate practices.

Factor 4 that is named as 'Occupational Stress' contains two variables, stress free work $\left(\mathrm{X}_{8}\right)$ and opportunity to use skill and talent $\left(\mathrm{X}_{10}\right)$. Both the variables ranked top of the chart (that is $1^{\text {st }}$ and $2^{\text {nd }}$ respectably). It is obvious that the job of MRs is not very stress free, as they need to fulfill targets within a given time and need to work long hours. They need to attain two key performance indicators (KPI). First, they are to fulfill the sales target based on product category and secondly the sales figure in financial account. MR's performance rating mostly depends on these two issues and they must be attained in a given time depending on the nature of demand and competition in the market. So, it becomes an obvious pressure game for most of the MRs which leads to lower QWL. The discussion mentioned above answers the second research question of the study.

\section{Conclusion and implication}

The core business of every pharmaceutical company is manufacturing, marketing, and distribution of pharmaceuticals products. But the sales lead of the products are mostly generated by the contribution of MRs. This study tried to explore reality of quality of work life of MRs from both positive and negative perspectives. The impacts of most of the variables are positive in ensuring QWL of MRs of Bangladeshi companies. But it is evident that, the profession is stressful and caries less dignity compared to other sales professions like the ones in telecommunication companies and multinational marketing companies. MRs need to work long hours and there is an absence of good interpersonal relationship among them. Better practice on management by objective (MBO) may reduce the job pressure of this profession. Companies need to plan for better job design and job enrichment practice to make the profession more dignified in the society. Nurturing teamwork among the MRs may enhance the cohesiveness that may lead to harmonious relationship among the colleagues thus load-sharing results to less stress. Management should realize that, MRs are the key workforce for the pharmaceutical companies. Excellence in QWL practice should be the 
top priority of the management to ensure productivity and profitability of the pharmaceutical companies through motivated MRs.

The study makes a considerable contribution to understand the importance of QWL as a standard human HRM practice. The research result may aid the managers, practitioners, and consultants to sculpt a better work life for the people who work under pressure. In terms of further research, there are great opportunities for the scholars to extend the scope of the research considering large sample size and different categories of respondents of the same or in other sector. Researchers could examine the relationship of QWL practice with the productivity and profitability of the organizations.

\section{References}

Akter, M., M. K. 2015. The pharmaceutical industry of Bangladesh, Bangladesh Textile Today, 8, April.

Bragard, I., Dupuis, G., Razavi, D., Reynaert, C. and Etienne, A. M. 2012. Quality of work life in doctors working with cancer patients. Occupational Medicine, 62, 34-40.

Bagtasos, M. R. 2011. Quality of Work Life: A Review of Literature. DLSU Business \& Economics Review, 20.

Bolhari, A., Rezaeean, A., Bolhari, J., Bairamzadeh, S. and Soltan, A. A. 2011. The relationship between quality of work life and demographic characteristics of information technology staffs. Age, 2, H1.

Ballou, B. and Godwin, N. H. 2007. Quality of" work life": have you invested in your organization's future?. Strategic Finance, 41-46.

Choudhury, T. A. and Zarrin, F. 2016, Market Pulse, Issue 106, February.

Cole, D. C., Robson, L. S., Lemieux-Charles, L., McGuire, W., Sicotte, C. and Champagne, F. 2005. Quality of working life indicators in Canadian health care organizations: a tool for healthy, health care workplaces? Occupational Medicine, 55, 54-59.

Carlson, H. C. 1981. Quality of work life model. Education+ Training, 23, 99-100.

Chander, S. and Singh, P. 1993. Quality of work life in a University: an empirical investigation. management and labour studies, 18, 97-107.

Gnanayudam, J. and Dharmasiri, A. 2007. The influence of quality of work-life on organizational commitment: a study of the apparel industry. Sri Lankan J. Management, 12.
Hossain, M. M. and Shoaib, S. M. 2013. Role of pharmaceutical sector in the national economy of Bangladesh. World J. Pharmacy Pharmaceut. Sci. 3, 951-960.

Habib, M. A. and Alam, M. Z. 2011. Business analysis of pharmaceutical firms in Bangladesh: problems and prospects. J. Busin. Technol. (Dhaka), 6, 61-77.

Huda, K. N. and Azad, A. K. 2015. Professional stress in journalism: a study on electronic media Journalists of Bangladesh. Adv. J. Commun. 3, 79.

Johnsrud, L. K. 2006. Studied on quality of faculty work life: the University of Hawaii.

Kiriago, A. N. and Bwisa, H. M. 2013. Working environment factors that affect quality of work life among attendants in petrol stations in Kitale town in Kenya. International J. Acad. Res. Busin. Social Sci. 3, 289.

Kaushik, N. and Tonk, M.S. 2008. Personality and quality of work life. The iCFAi J. Organization. Behavior, 7, 34-46

Krueger, P., Brazil, K., Lohfeld, L., Edward, H.G., Lewis, D. and Tjam, E. 2002. Organization specific predictors of job satisfaction from a Canadian multi-site quality of work life cross-cultural survey. BMC Health Services Res. 2. Retrieved September 12,2008, from http://www.biomedcentral.com/1472- 6963/2/6

Li, J. and Yeo, R.K. 2011. Quality of work life and career development: perceptions of part-time MBA students, Employee Relations

Mohammadi, H. and Shahrabi, M. 2013. A study on relationship between quality of work life and job satisfaction. Manag. Sci. Letters, 3, 2675-2680.

Nair, G. S. 2013. A study on the effect of quality of work life on organizational citizenship behavior-With Special reference to College Teachers is Thrissur District, Kerala. Integral Review, 6.

Padala, S.R. and Suryanarayana, NVS 2010. Industrial safety and quality of work life. Retrieved September 23, 2010, from http:// www.articlesbase.com/environment-articles/ industrial-safety-and-quality-of-work-life-

Parker, C. P., Baltes, B. B., Young, S. A., Huff, J. W., Altmann, R. A., Lacost, H. A. and Roberts, J. E. 2003. Relationships between psychological climate perceptions and work outcomes: a metaanalytic review. $J$. Organization. Behavior 4, 389-416.

Quality of working life survey, Cardiff University, 2008. Unite (Amicus). London. Retrieved April 4, 2008, from www.qowl. eo.ukWyatt, T.A

Rice, R.W., McFarlin, D.B., Hunt, R.G. and Near, J.P. 1985, Organizational work and the perceived quality of life: toward a conceptual model. Acad. Manage. Rev. 10, 296310. 
Sultana, J. 2016. Future prospects and barriers of pharmaceutical Industries in Bangladesh, Bangladesh Pharm.. J. 19, 53-57.

Sadri, S. and Goveas, C. 2013. Sustainable quality of work life and job satisfaction [an Indian case study]. J. Econ. Develop. Environ. People 2, 26-37.

Sirgy, M. J., Efraty, D., Siegel, P. and Lee, D.J. 2001, 'A new measure of quality of work life (QWL) based on need satisfaction and spillover theories', Social Indicators Res. 55, 241-302.

Tabassum, A., Rahman, T. and Jahan, K. U. R. S. I. A. 2011. Quality of work life among male and female employees of private commercial banks in Bangladesh. Int. J. Econ. Manage. 5, 266-282.
Vagharseyyedin, S. A., Vanaki, Z. and Mohammadi, E. 2011. Quality of work life: experiences of Iranian nurses. Nursing Health Sci. 13, 65-75.

Yadav, R. and Khanna, A. 2014. Literature review on quality of work life and their dimensions, IOSR J. Human. Social Sci. 19, 71-80

Yeo, R. K. and Li, J. 2011. Working out the quality of work life: a career development perspective with insights for human resource management. Human Resour. Manage. Int. Digests 19, 39-45. 